\title{
Behavior of railroads on shrink-swell soils
}

\author{
Dong Wang ${ }^{1}$, Marcelo Sánchez ${ }^{1, a}$ Jean-Louis Briaud $^{1}$ \\ ${ }^{1}$ Zachry Department of Civil Engineering, Texas A\&M University, College Station, USA
}

\begin{abstract}
Shrink-swell soils are characterized by significant volume expansions and contractions during wetting and drying processes, respectively. Railroads on shrink-swell soils are subjected to huge solicitations associated with the volume change of the soil. The highly permeable ballast layer exacerbates soil volume changes due to moisture variation, which generally lead to unacceptable uneven settlement. The mechanism behind the observed railroads problems on expansive soils, and the associated (possible) remedial solutions, are still unclear. A site in Texas has been chosen recently to study in detail the aforementioned problems. In this paper, the typical geomechanical problems associated with railroads on shrink-swell soils in Texas are discussed. We also presented the test site information and preliminary lab tests to obtain water retention curve of the site soils.
\end{abstract}

\section{Introduction}

Railroad embankments and subgrades are subjected not only to cyclic train loadings (which has been continuously increasing due to freight requirement), but also to weather variations. Texas, and many other regions in the world with abundant shrink-swell soil has been observing continuous settlement problems. The settlement problems in Texas become especially severe in harsh weather condition such as during the drought summer of 2011 with an average of only $37.6 \mathrm{~cm}$ of rain over the year. On the other hand, in October 2015, when a storm with $50 \mathrm{~cm}$ daily rainfall hit Texas, train derailed passing by a soaked embankment in the flood region.

Existing railroads in the United States are facing challenging geotechnical problems, such as i) slurry pumping (e.g.[1]); ii) subgrade subsidence (e.g.[2]); iii) progressive shear failure (e.g.[3]); iv) ballast pocket (e.g.[4]); v) massive shear failure (e.g.[5]); vi) subgrade cavities and collapse (e.g.[6]); vii) issues associated with expansive soil behaviour (e.g.[7]); and viii) problems related to frozen soils (e.g.[8]). Typical problems observed in Texas railroads are types (i), (ii), (iii), (iv), and (vii), as described above. To advance our understanding on the mechanism of the aforementioned subgrade problems, we selected a test railroad site in Texas to study in detail the interactions between railroad, natural soils, and weather variations. This work is in progress. In this paper we present some preliminary site investigation alongside a literature review and preliminary lab test results on water retention curve.

\section{Typical railroad problems in Texas}

As the state with highest expansive soil coverage in the United States, Texas encountered railroads settlement problems not only related to subgrades, but also embankments, because local shrink-swell soils have been historically used as fill materials.

The problems of expansive soils are aggravated in areas where moisture changes repeatedly. Significant volume changes observed in these soils have very negative impact on the long term performance of railroads. Uneven longitudinal and transversal settlements are very characteristics in railways constructed in swellshrink soils.

Different factors can be associated with the development of uneven railroad settlements in shrinkswell soils. For example, non-homogeneous distributions of soils properties may induce different volume changes in different zones, leading to uneven settlements. Nonhomogeneous distribution of moisture in the ground can also induce uneven settlements. For instance, the presence of trees close to the railroad may lead to important changes in the distribution of water content. Relatively high matric suction can develop in the root zone, which alter the distribution of matric suction in the surrounding soil with the consequence of the associated soil shrinkage. A non-homogeneous distribution of water content can also be related to other factors, as for example local topographic conditions. Sometimes railroad acts as an artificial barrier for the movement of the run-off water. Despite the proper design of culvert and drains, it is quite common to observe after intense rains ponding water at one side of the embankment. Figure 1.a) represents this problem schematically showing a railroad embankment crossing a terrain with a natural gradient. Under this scenario, the water accumulated on one side of the embankment will

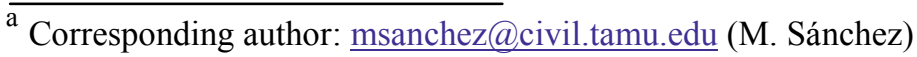


infiltrate, wetting the natural soils and embankment leading to the expansion of the swelling clays. The other side of the embankment will be exposed to dry air and the soils will shrink. The final outcome is uneven transversal settlements of the railroad (Figure 1.b).

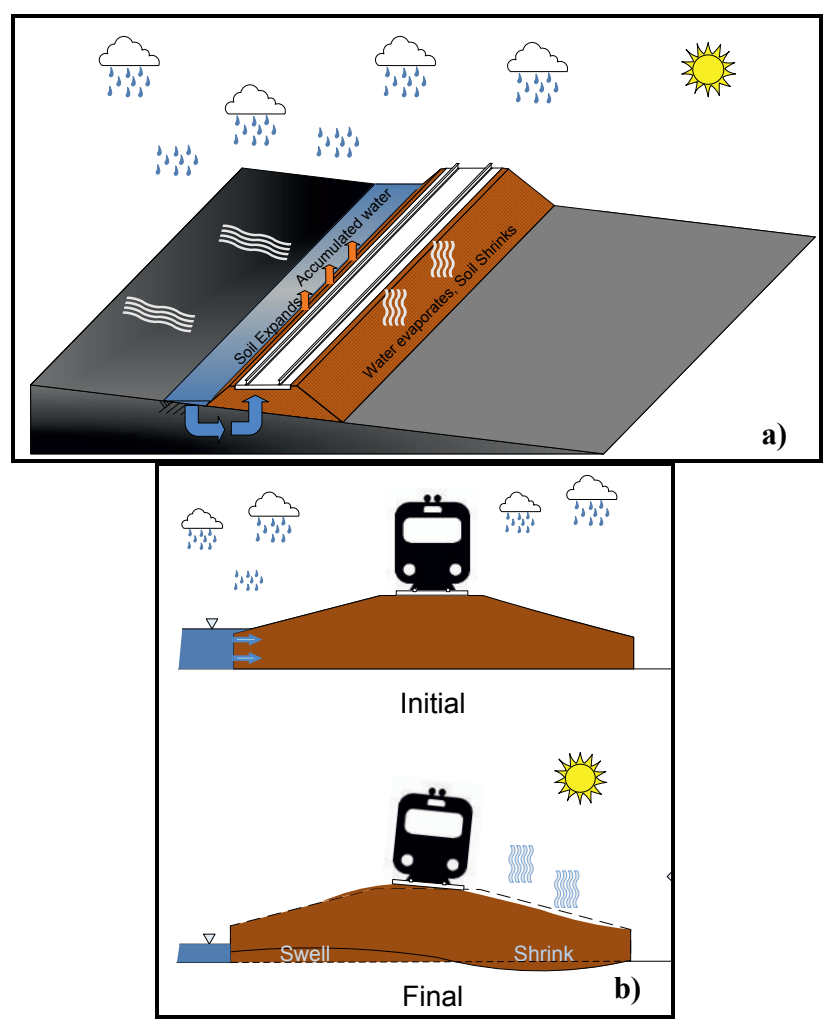

Figure 1. Potential effect of ponding water on one side of the railroad, a) 3D schematic representation, b) uneven settlements induced by wetting and drying of shrink-swell soils.

Another problem associated with expansive clays is the formation of cracks during drying. Cracks affect both mechanical and hydraulic properties of soils. Drying cracks extend the 'active zone' of expansive clays because the movement of water is favoured by the presence of vertical cracks (e.g.[9]). The presence of drying cracks in rail embankments may trigger stability problems, associated e.g. with the internal erosion induced by the water flowing through cracks ay higher velocities.

The presence of 'ballast pocket' is also very common in Texas railroads. As ballast is pushed into subgrade due to the train load, the underlying subgrade will form a pocket-like structure in which ballast is held inside. Ballast pocket usually occurs in sections with soft clays. The formation of ballast pocket is triggered because ties tend to form water-trapping ponds (e.g. with water from rains). This water gradually infiltrates through the ballast and saturates the underlying soft subgrade soils. The train dynamic loads reduce the effective stresses of the subgrade and the soils deform. Discrete cavities are then formed under each tie. Once these cavities are formed, rainfall and ground water will be conducted into deeper layers in the subgrade. In this way, a vicious circle continues, leading to the formation of large cavities when discrete ballast pockets connect to each other. Figure 2 shows a typical ballast pocket.

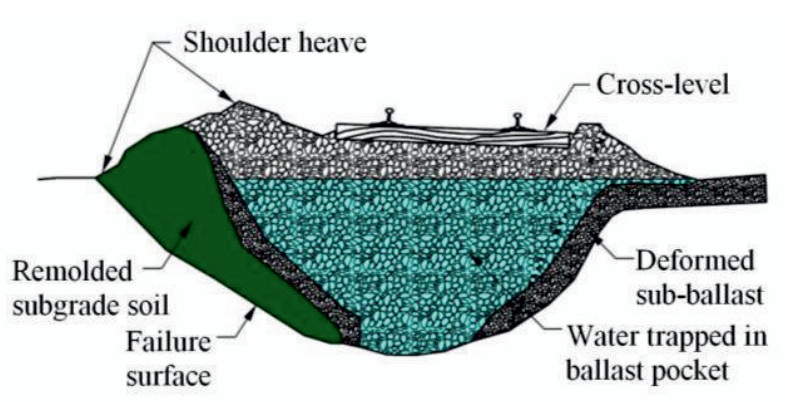

Figure 2. A sketch of railroad ballast pocket [10]

Progressive shear failure is another mechanism that can be responsible for uneven settlements in railroads in clayey subgrades (e.g.[3]). This failure mode will most likely develop in the top part of the subgrade, especially when a soft upper layer overlaid a rigid one. The trains load causes a higher stress concentration on the top layer. Overstressed clays are progressively squeezed sideways and upwards [3]. In the United Kingdom, this failure is known as 'Cess Heave'[11].

'Slurry pumping' is another phenomenon that has been observed in Texas. This phenomenon occurs in sections where the subgrade soil is hard, fine grained and poorly drained. It develops in stages, starting with water accumulation, continuing with local slurry pumping, and finishing with large-range slurry pumping. Generally the slurry pumped from the subgrade infiltrates into the ballast layer and coagulates with the ballast and ends up with a bonded crust layer. This causes uneven strength in the ballast. Variation of moisture in the slurry, once it migrates to the ballast layer, may also occur. Furthermore, infiltrated water (e.g. through small cracks and fissures in the crust layer) is subjected to huge pressure induced by the relatively closed space and dynamic train loading. This high pressure assists the pumping of slurry and another cycle starts. Ties lying on this kind of ballast are under uneven loading and will be prone to damage.

\section{Test site}

We found few publications reporting remedial solutions for railroads on shrink-swell soils. To advance our understanding in this area, a railroad test-site on shrinkswell soils has been selected to investigate in detail possible remedial solutions.

The test site is a single main track with an annual tonnage of 58 MGT. The issue of slow orders is very frequent. Particularly dramatic was the very dry summer of 2011, a large number of slow orders was issued. Based on this fact we hypothesize the shrinkage of local soils upon drying is the main problem.

\subsection{Site location}

Figure 3 presents a map with the distribution of swelling clays around the area of Texas. It can be observed that the soil units with the most high expansive potential clays, (i.e. unit in red), and soils that contain abundant content of swelling potential clays (i.e. unit in blue) dominate the 
soils in Texas. The location of the selected test site falls in the red zone.

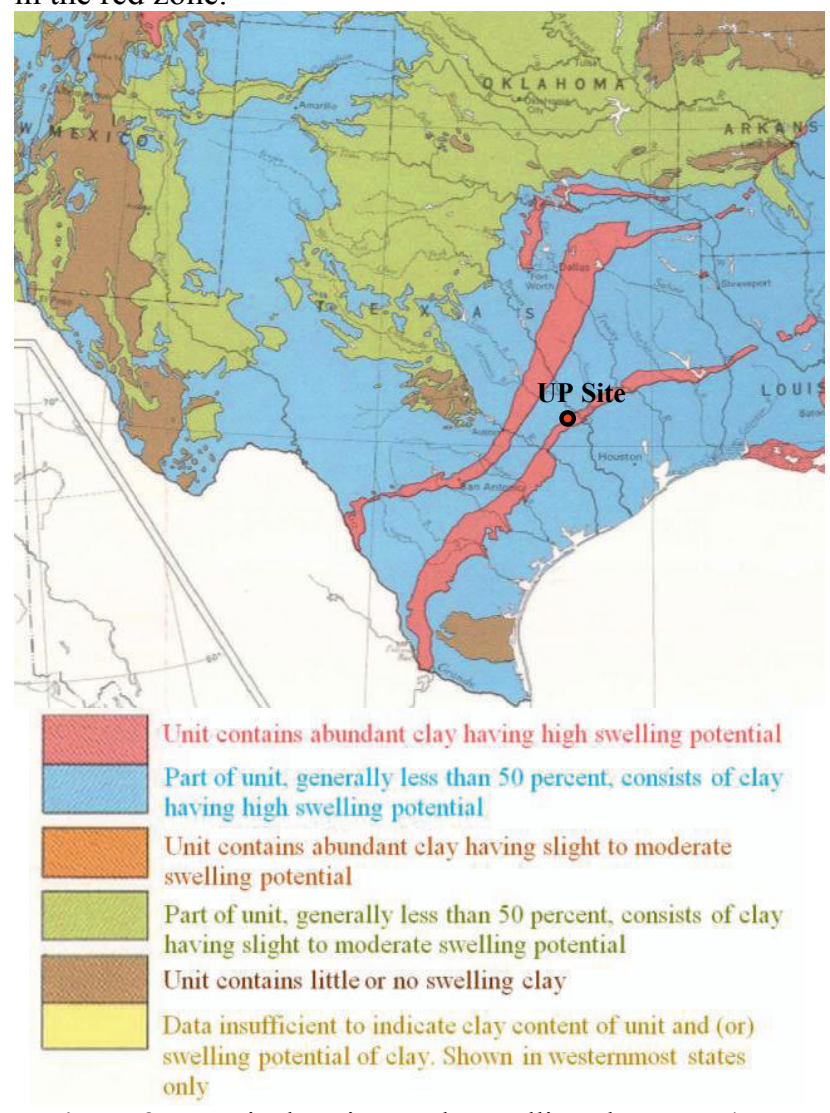

Figure 3. Test site location on the swelling clays map (map from [12])

As explained above, expansive soils experience large volume changes upon moisture changes. They also develop permanent deformations during wet and dry cycles. Therefore, it is of interest to look at the interaction between soil and atmosphere. The Thormthwaite Moisture Index (TMI,[13]) is a very good indicator of the hydraulic balance between soil and atmosphere. It relates the supply of water (precipitation) to the soil to the potential evaporation. In this context, a moist climate has a positive TMI and a dry one has a negative TMI. Figure 4 shows the TMI map for Texas. It is noted that the test site is at a $\mathrm{TMI}=0$ region. This implies a perfect balance between precipitation and evaporation at this location.

Figure 5 shows the monthly average precipitation from year 1971 to 2000 at the site. Two dry seasons (DS) and two wet seasons (WS) can be noted each year. This is a very unfavourable weather condition for swell-shrink soils, because the soil is exposed to two balanced (according to the TMI) wet-dry cycles.

The field investigation focuses on two main problematic sections: a cut and a fill section. A reference section with similar properties to the previous ones, but with no major problems reported in the past was chosen as a control group. The proposed field study encompasses two main components: long term monitoring, and site investigation. More details can be found elsewhere [14].

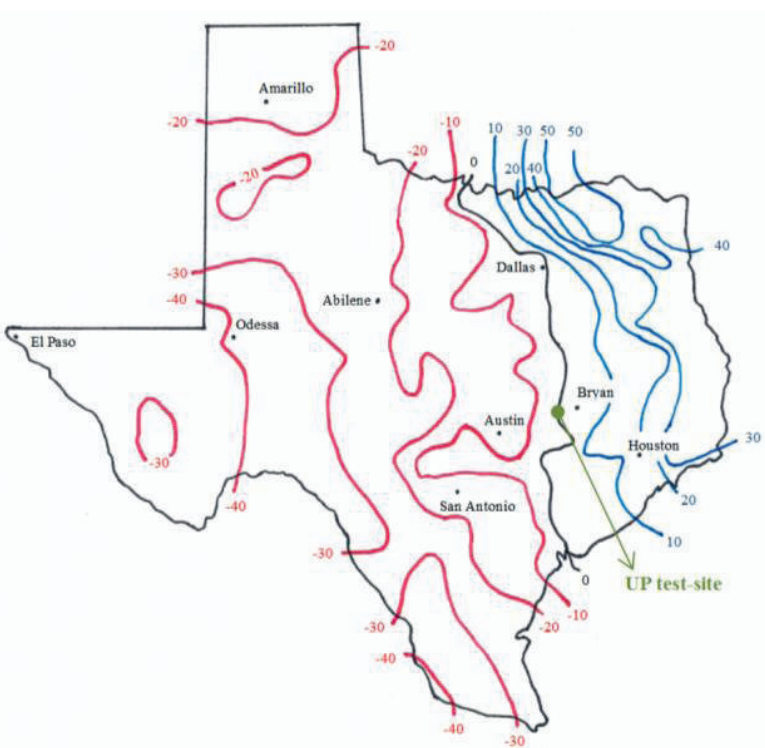

Figure 4. Thornthwaite Moisture Index for Texas [13]

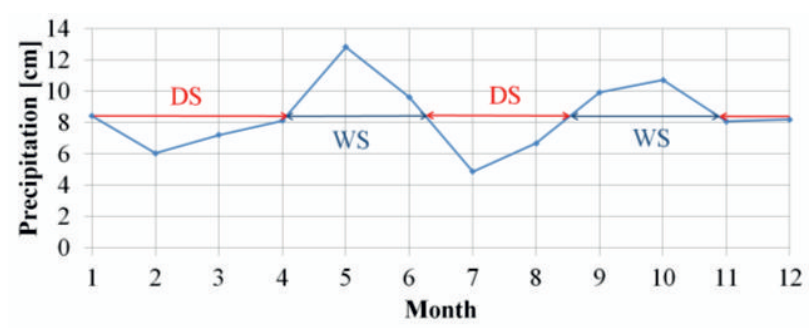

Figure 5. Monthly average precipitation (U.S. Climate Normals 1971-2000) in the area under study

\subsection{Proposed monitoring}

There are two main aspects that we want to monitor: i) soil movements, and ii) changes in soil moisture content at different depths. The study of soil movements is essential for diagnosis and understanding of the mechanisms behind the observed settlements. It is also crucial to tack the variation of the moisture content, because expansive soils respond with large volume changes upon moisture variations. For a continuous and unattended monitoring of the transversal movements at the cut and fill sections we have installed two track twist sensors [15] (one at the fill section, the other at the cut section) at site. The monitoring of the movements will be completed with inclinometer readings at the three selected sections. To measure the absolute embankment settlements, a benchmark resting on the bedrock was installed near the fill section. As for the monitoring of the variation of soil moisture, we have selected the EnviroSCAN multisensors to measure the moisture content profiles at the cut and fill sections in a continuous and automatic manner. This sensor is based on frequency domain reflectometry to measure soil volumetric water content. It can monitor moisture content from shallow depths (i.e. 0 to $10[\mathrm{~cm}]$ ) up to very deep positions (around $40[\mathrm{~m}]$ ), and a maximum of 16 sensors can be included in one probe. A data acquisition system is installed at the site for automatic data collection of the two twist sensors and two moisture probes every 6 hours. 


\subsection{Site investigation}

The site investigation had the following multiple objectives: i) to gather soil samples; ii) to perform the insitu tests, iii) to install the twist sensors, water content probes and data acquisition system; iv) to install inclinometer casings; v) to install the monitoring well; and vi) to construct the surveying benchmark. Figure 6 presents a detailed description for the fill section. The section profile, soil stratigraphy, instrumentation layout, and SPT blow counts are included in Figure 6. The cut section has a similar instrumentation layout. According to the USCS Classification System, the soil types in both sections are mainly high plasticity clays.

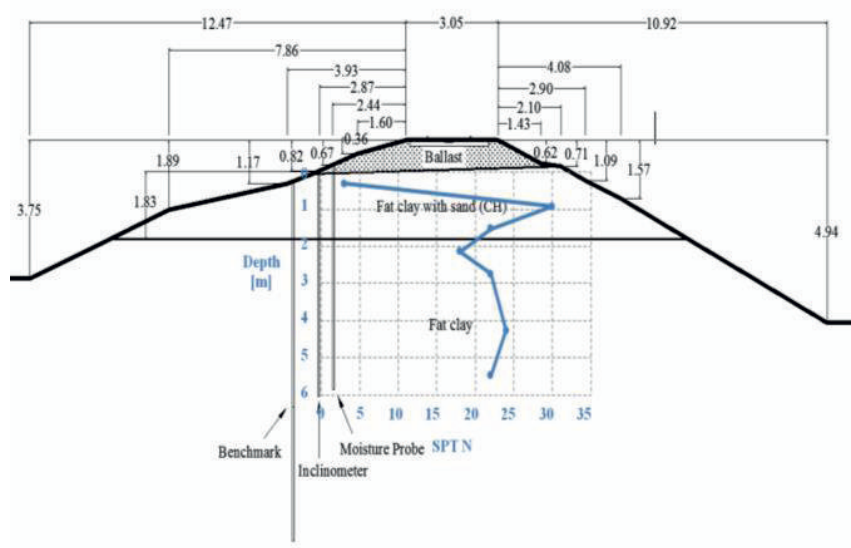

Figure 6. UP test site profile and instrumentation layout at the fill section

\section{Soil water retention curve test}

Water retention curve is the relationship between suction and water content (or degree of saturation) in soils. There are many techniques to measure suction in soils, such as tensiometer, Fredlund thermal conductivity sensor, Decagon WP4C, capacitive hygrometer, and filter paper. In this paper, filter paper and WP4 device are used to measure soil suction values. The filter paper test is an easy and cheap lab test which can readily be carried out in laboratories; however it requires sometime to obtain the results. The Decagon WP4 device, on the other hand, provide soil suction values in minutes. Both techniques are applied on the site soil and the results are compared.

\subsection{Filter paper test}

Reconstituted samples were statically compacted to the same dry density as observed in the site in order to capture the natural condition characteristics. The natural samples were firstly air dried. Then, they were grinded and sieved. All soil particles passed No. 40 sieve. Reconstituted soil samples were made according to the weight percentage retained on different size sieves.

A known volume (i.e. $155.68 \mathrm{~cm}^{3}$ ) split container was used for sample compaction. Based on the known volume and known dry density the necessary dry soil mass was calculated. The hydroscopic water content was considered when calculating the amount of water needed. The target degree of saturation and its corresponding water content needed in a soil sample with dry density $=1.465 \mathrm{~g} / \mathrm{cm}^{3}$ is shown in Table 1 . A larger number of samples were prepared around the saturated condition to detect the air entry value. Over saturated samples were prepared in order to ensure saturated condition. Degree of saturation were recalculated after the test by measuring the final sample water content.

Table 1. Target water content in sample for different degrees of saturation

\begin{tabular}{|c|c|c|c|}
\hline $\begin{array}{c}\text { Target degree } \\
\text { of saturation }\end{array}$ & $\begin{array}{c}\text { Target water } \\
\text { content }\end{array}$ & $\begin{array}{c}\text { water mass } \\
\text { needed in dry } \\
\text { soil }(\mathrm{g})\end{array}$ & $\begin{array}{c}\text { water mass } \\
\text { needed in air } \\
\text { dry soil } \\
\text { powders }(\mathrm{g})\end{array}$ \\
\hline 1.1 & 0.335980895 & 76.60613 & 63.3218 \\
\hline 1.05 & 0.320709036 & 73.12403 & 59.8397 \\
\hline 1 & 0.305437177 & 69.64194 & 56.35761 \\
\hline 0.95 & 0.290165318 & 66.15984 & 52.87551 \\
\hline 0.9 & 0.274893459 & 62.67774 & 49.39341 \\
\hline 0.7 & 0.213806 & 48.74936 & 35.46503 \\
\hline 0.5 & 0.152719 & 34.82097 & 21.53664 \\
\hline 0.3 & 0.091631 & 20.89258 & 20.89258 \\
\hline
\end{tabular}

After mixing the soil powders with required amount of water, the wetted soil powders were sealed in plastic bags and stored in the moisture room for 24 hours for moisture redistribution in the sample. Then the samples were compacted to target volume $\left(155.68 \mathrm{~cm}^{3}\right)$ so that all samples have the same dry density.

The ASTM D5298-10 was followed to carry out the filter paper tests. The equilibrium time for this test was around 2 weeks. In order to compare the effect of the dry density on water retention, another set of filter paper test on the same soil sample with a different dry density $=1.221 \mathrm{~g} / \mathrm{cm}^{3}$ was also carried out.

\subsection{WP4 test}

The WP4 device is a fast instrument based on the chilledmirror dewpoint technique to measure the water potential. The sample was sealed in a small space with the ceiling of a mirror and a means of detecting condensation on the mirror. At equilibrium, the water potential of the air in the chamber is the same as the water potential of the sample. [16]

After finishing the filter paper test, a small portion of the sample was taken and placed in the WP4 device for water potential test. The test results for both the filter paper test and WP4 device are presented in the following Section

\subsection{Water retention curve results}

The water retention curve results tested by filter paper method and the WP4 method are shown in Figure 7. 


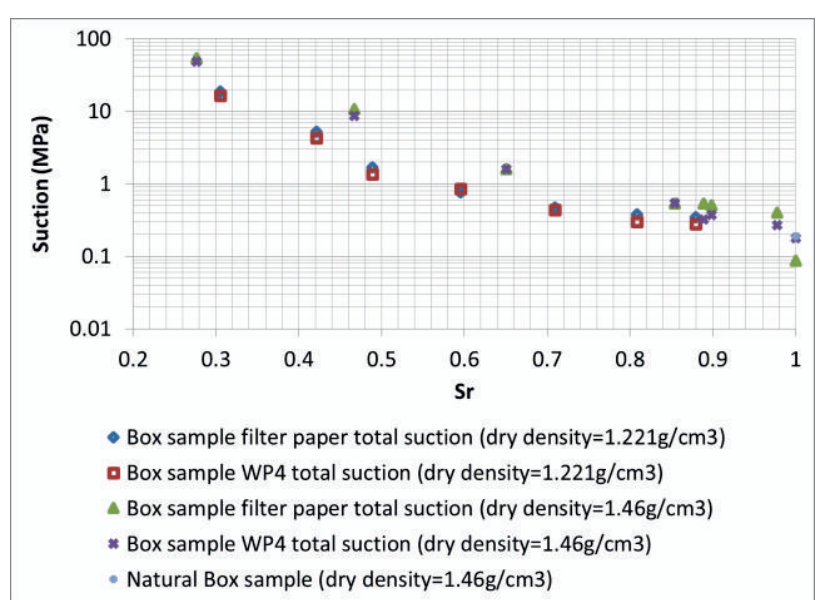

Figure 7. Water retention curves using filter paper method and WP4 method on different dry density soils.

It can be seen from Figure 7 that the filter paper method and the WP4 method gives quite similar results. The air entry value for the site soil is around $500 \mathrm{kPa}$. It can also be observed that the reconstituted soil sample gives the same suction value as the natural sample. As expected, the lower dry density soil has less capacity to retain water in the soil skeleton under the same suction condition than higher dry density soils.

\section{Summary and conclusion}

In this paper we focused the attention on typical geotechnical problems observed in Texas railroads. Severe damages in railroads on shrink-swell soils (generally associated with uneven settlements) are induced by moisture changes of the subgrade and embankments, both composed of expansive clay minerals. In this paper we discussed in detail the different problems observed in these types of railroads. It is not obvious that remedial solutions for expansive soils typically used in building constructions and roads can be directly applied to railroads. Because of that, a test site in Texas was recently selected to study the performance of railroads on expansive soils. The main aspects of the test site, including the monitoring instrumentation and site investigation are discussed. From the site investigation, it was confirmed that the dominant soils at the test site correspond to high plasticity expansive clays. As part of the lab investigation. filter paper and WP4 test were carried out for the in-situ soils. Test results using these two different techniques show good agreement. This is a work in progress, following stages are associated with continuous monitoring of settlements and moisture changes, suction-controlled lab tests such as consolidation test, the proposal of possible remedial solutions and also the numerical modelling.

\section{References}

1. T.V. Duong, Y.J. Cui, A.M. Tang, J.C. Dupla, J. Canou, N. Calon, A. Robinet. Engineering Geology 171, 45-58 (2014)

2. Y. Luo, S.S. Peng. Proc. 13th international conference, ground control in mining, Morgantown, WV, 308-319 (1994)

3. E.T. Selig, J.M. Waters. Track Geotechnology and Substructure Management, Thomas Telford (1994)

4. D.Q. Li, E.T. Selig. J. Geotech. and Geoenviron. Eng. 124(4) 316-322 (1998)

5. R.J. Chandler, M. Pachakis, J. Mercer, J. Wrightman. Quarterly Journal of Engineering Geology and Hydrogeology 6, 405-422 (1973)

6. R.L. Zhang, Q.C. Wang, J. Zhang. Subgrade Engineering 4, 58-61 (2010)

7. S.W. Liao. Expansive soil and railway engineering, Chinese Railway Publishing Press, Beijing (1984)

8. W. Ma, G. Cheng, Q. Wu. Cold Regions Science and Technology 59, 3-11 (2009)

9. M. Flury, H. Fluhler, W.A. Jury, J. Leuenberger. Water resources research 30 (7), 1945-1954 (1994)

10. Union Pacific. Union Pacific railroad engineering strandards: Trench drains (2011)

11. M.P.N. Burrow, D. Bowness, G.S. Ghataora. Journal of Rail and Rapid Transit 221(1),1-12 (2007)

12. W.W. Olilve, A.F. Chleborad, C.W. Frahme, J. Schlocker, R.R. Schneider, R.L. Schuster. Swelling clays map of the conterminous United States. Dept. Interior US Geological Survey (1989)

13. W.K. Wary. PhD dissertation, Texas A\&M University, College Station (1978)

14. M. Sanchez, D. Wang, J.L. Briaud, C. Douglas. Transportation Geotechnics 1, 257-275 (2014)

15. DGSI. EL Track Monitoring System (2008)

16. Decagon Devices, Inc. Wp4 Operator's Manual Version 2.1 